\title{
Nocturia: state of the art and critical analysis of current assessment and treatment strategies
}

\author{
Matthias Oelke • Erika Adler • Daniela Marschall-Kehrel • \\ Thomas R. W. Herrmann • Richard Berges
}

Published online: 13 September 2014

(C) Springer-Verlag Berlin Heidelberg 2014

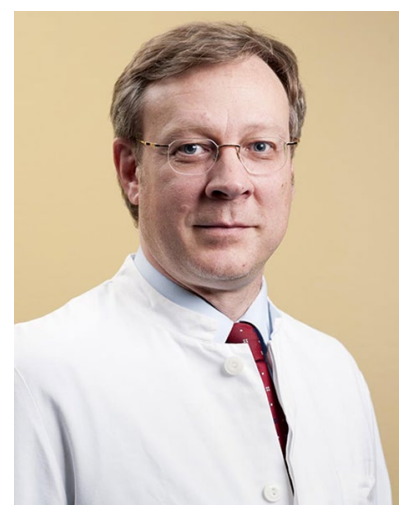

Matthias Oelke

\begin{abstract}
This editorial of the topic issue of the World Journal of Urology provides a state of the art on nocturia which includes descriptions of the terminology, epidemiology, health-related quality of life, medical and financial consequences, pathophysiology, assessment tools and treatment strategies of nocturia. This summary also includes a flowchart on the pathophysiology of nocturia with illustration of the various causes of reduced bladder capacity, increased fluid intake or increased diuresis; a flowchart with the key findings of frequency-volume charts to determine the underlying pathophysiology; and a flowchart on
\end{abstract}

\footnotetext{
M. Oelke $(\varangle) \cdot$ E. Adler · T. R. W. Herrmann Department of Urology, OE 6240, Hannover Medical School, 30625 Hannover, Germany

e-mail: oelke.matthias@mh-hannover.de

D. Marschall-Kehrel

Urology Consultancy, Frankfurt-Main, Germany

R. Berges

Department of Urology, PAN-Klinik, Cologne, Germany
}

the treatment of the various causes of nocturia. The editorial critically discusses current assessment and treatment strategies in patients with lower urinary tract symptoms suggestive of benign prostatic hyperplasia (LUTS/BPH) and nocturia. The outcome of nocturia remains hidden in drug trials of patients with LUTS/BPH because nocturiaspecific measures were not included. The authors recommend using frequency-volume charts, measurement of the hours of undisturbed sleep, and nocturia-specific quality of life questionnaires (e.g., ICIQ-N or N-Qol) in all future studies in patients with LUTS/BPH and nocturia.

Keywords Nocturia - Lower urinary tract symptoms . Benign prostatic hyperplasia . Outcome assessment

\section{Terminology}

The terminology of and around nocturia may be unknown or confusing; therefore, the terminology is briefly presented and discussed once more because it has implications on the results of studies presented in this topic issue on nocturia of the World Journal of Urology. Nocturia has been defined by experts of the International Continence Society (ICS) as the general complaint that the individual (independent of age, gender, cause(s) and associated bother) has to wake at night one or more times to void $[1,2]$. The definition also includes that nocturnal voids are preceded and followed by sleep. In contrast, nighttime frequency or nocturnal voiding frequency is the term used to describe the number of nocturnal voids without specially excluding sleep before or after emptying the bladder [2]. Therefore, nocturia and nighttime frequency may be identical but the terms are not interchangeable, unless specific information about sleep is available. These specific definitions imply that the vast 
majority of published trials on nocturia are actually trials on nighttime frequency because sleep before or after voiding during the night was rarely documented.

The definition of nocturia also suggests consciousness of a full bladder and a compelling desire to void which motivates the individual to wake and voluntarily use the toilet during the night. In contrast, nocturnal enuresis is also nighttime voiding, but the individual is not aware of a full bladder, does not awake and empties urine involuntarily in the bed during the nighttime; therefore, nocturia and nocturnal enuresis are distinguishable by the alertness of a full bladder and waking up to void [2]. Nighttime is defined as the period of going to bed with the intention of sleeping and waking up with the intention of arising [2]. There may appear confusion with the definition of nighttime in shiftworkers who work at night and sleep during the day. In this particular group, sleep during the day is considered nighttime and any void during this sleeping period is considered nocturia [2].

Nocturia specifically is the number of voids recorded during the nighttime [2]. The first morning void is excluded from the count because it is not followed by sleep. Nocturnal urine volume describes the amount of urine excreted during the nighttime and also includes the volume of the first morning void because this urine has been produced during the nighttime [2]. Nocturnal polyuria is an abnormally large urine volume produced during the nighttime. The ICS classifies nocturnal polyuria as the nocturnal urine volume divided by the 24 -h urine volume (i.e., nocturnal polyuria index, NPi) [2]. NPi increases with aging and is approximately $14 \%$ in healthy individuals aged 21-35 years (95 \% confidence interval 10-19 \%) and approximately $34 \%$ in adults aged $>65$ years $(95 \%$ confidence interval 30-36 \%). To simply matter, the ICS defines nocturnal polyuria as NPi $>20 \%$ in young individuals and $>33 \%$ in elderly [2].

\section{Epidemiology}

Epidemiological trials in different countries have drawn attention to high prevalence rates of nocturia/nighttime frequency in community-dwelling men and women worldwide. In general, nocturia (independent on cause(s) and associated bother) increases with aging and affects both men and women equally [3, 4]. In an analysis of 43 trials, $11.0-35.2 \%$ of men aged $20-40$ years reported about nocturia $\geq 1$ times per night and $2.0-16.6 \%$ of men about nocturia $\geq 2$ times per night [4]. In men $>70$ years of age, the prevalence rates of nocturia $\geq 1$ times per night rose to $68.9-93.0 \%$ and $\geq 2$ times per night to $29.0-59.3 \%$. This topic issue of the World Journal of Urology on nocturia also contains the first report on nocturia in German community-dwelling men in which $87 \%$ of men aged 50-80 years reported about nocturia $\geq 1$ times per night and $43 \%$ of men $\geq 2$ times per night [5]. This study confirmed the high prevalence rates in Germany and is in line with the results of other epidemiological studies.

\section{Health-related quality of life}

The definition of nocturia does not contain any information on bother or deterioration of health-related quality of life (HRQoL). However, this information is crucial as it could explain health-care seeking behavior and medical consultations of the affected people. Several studies have shown that nocturia is not only the most frequently reported symptom of all lower urinary tract symptoms (LUTS) in men but is also perceived as (one of) the most bothersome. Although the perception of bother associated with nocturia largely depends on the individual, the FINNO study reported bother from nocturia when the individual has to void at least 2 times per night (i.e., clinically relevant nocturia) [3]. The German epidemiological study on nocturia, first presented in this topic issue, confirmed this threshold value in adult men and showed that $\geq 2$ voids per night significantly reduces HRQoL (as measured by the SF-12 questionnaire and the IPSS-QoL index) and is the only symptom of all LUTS captured on the IPSS questionnaire that triggers medical consultations in the 2-year follow-up period [5]. The higher the nocturnal voiding frequency was, the more deteriorated the HRQoL became. Because the participants evaluated in this study are representative of the German male population, the authors were able to calculate the total number of affected people: there are an estimated number of 5.83 million German men with $\geq 2$ nocturnal voids of which approximately 1.8 million men seek professional help for nocturia. These numbers in only one country and only in adult men demonstrate the proportion of the medical problem associated with nocturia in Germany and worldwide.

\section{Medical and financial consequences of nocturia}

Nocturia is not only bothersome for the individual but can also have a profound impact on health and health care. Nocturia has been identified as the leading cause for sleep disturbance and sleep fragmentation, causes daytime fatigue, impacts daily activities, and deteriorates psychomotor performance, cognitive function and mood [6-9]. Nocturia can also cause depression, immune suppression, increases vulnerability for cardiovascular diseases and the development of diabetes mellitus [7, 10-12]. Additionally, nocturia ( $\geq 2$ times per night) significantly increases accidents, falls and 
fractures [13-17]. The costs associated with nocturia are tremendous and alarming. Nocturia can cause direct, indirect and intangible costs [18]. Only the direct annual costs of (hip) fractures were estimated to be approximately $\$ 1.5$ billion in the US and approximately $€ 1$ billion in the 15 largest countries of the European Union [18]. Indirect costs of nocturia are for example loss or impairment of work productivity, and those numbers are even more alarming. It was calculated that the annual loss of work productivity due to nocturia amounts for approximately $\$ 62.5$ billion in the US and approximately $€ 29$ billion in the 15 largest countries of the European Union [18]. Therefore, societies must have a fundamental interest to diagnose and treat nocturia to reduce morbidity and costs.

\section{Pathophysiology}

Nocturia has a multifactorial etiology, and the various causes often overstep the borders of individual medical specialties. Therefore, a broad spectrum of medical professionals deal with nocturia patients, including, besides others, urologists, gynecologists, nephrologists, cardiologists, pulmonologists, angiologists, psychiatrists, general practitioners and family care physicians. As many doctors tend to assess symptoms only within their medical specialty and not beyond the scope of their specialization, this may cause doubt or uncertainty about the underlying pathophysiology in the individual patient and, consequently, underdiagnosis and undertreatment of patients with nocturia. It becomes evident that a medical specialty or specialized doctors within this specialty need to focus on nocturia, follow generally accepted assessment paths and initiate nocturia-specific treatments based on the underlying pathophysiology. Once the pathophysiology has been clarified and a diagnosis established, it is acceptable to consult other medical specialties for support thereafter.

Nocturia in principle can be caused by reduced bladder capacity (anatomical, functional), increased fluid intake (during the 24-h period or in the evening/night) or increased diuresis (during the 24-h period or during nighttime only) [2]. An overview of the various causes is shown in Fig. 1. It was shown in adult urological patients with nocturia that more than $80 \%$ of men had nocturnal polyuria (NPi $>33 \%$ ) of whom $20 \%$ had nocturnal polyuria alone and more than $60 \%$ had nocturnal polyuria in combination with a decreased functional bladder capacity due to LUTS suggestive of benign prostatic hyperplasia (LUTS/BPH) or benign prostatic obstruction [19]. Physicians need to be aware that a single person may have more than one cause of nocturia. Therefore, thorough assessment of nocturia and its various causes is mandatory before treatment initiation.

\section{Assessment}

The key diagnostic tool to capture, quantify and evaluate the origin (pathophysiology) of nocturia is the frequencyvolume chart for 24-72 h. Frequency-volume charts objectively document the time of each void, voided volume per micturition, time of going to bed with the intention of sleeping and the time of waking up with the intention of starting the day; optional assessments are the ingested fluid volume, type of fluid and pad use in case of urinary incontinence (bladder diaries). Frequency-volume charts can distinguish between global polyuria (i.e., 24-h urine volume $>40 \mathrm{ml} / \mathrm{kg}$ bodyweight), nocturnal polyuria (i.e., nighttime urine volume $>20 \%$ in younger and $>33 \%$ in older adults in relation to 24-h urine volume) and reduced (anatomical or functional) bladder capacity (i.e., frequent voiding with low voided volumes) [2]. These quick and cheap tests can therefore discriminate between the major causes of nocturia and can identify the underlying pathophysiology (Fig. 2). The basic diagnostic workup for urological patients with nocturia further includes patient history and documentation of currently used drugs, physical investigation with digito-rectal examination in men, validated symptom questionnaires, urinalysis and measurement of postvoid residual volume. However, additional tests may be necessary in individual patients to evaluate the exact origin of LUTS and nocturia, such as uroflowmetry, computerurodynamic evaluation of bladder function, cystoscopy, bladder biopsies, blood analyses, sleep lab evaluation or specific cardiology tests (e.g., electrocardiography, echocardiography, magnetic resonance imaging of the chest or coronary angiography).

Nocturia-specific instruments may be useful to clarify the time of undisturbed sleep and degree of HRQoL reduction. These disease-specific instruments are particularly useful for the research, for example for the evaluation of drug effects on nocturia. However, these nocturia-specific instruments have had a limited role in routine patients until now. The hours of undisturbed sleep can be measured with a chronograph either by the patient or spouse. Reduction of the first sleep period, which consists of deep restorative slow wave sleep (SWS) and usually occurs during the first 3-4 h of sleep, has a negative effect on sleep quality. Disruption of SWS, even without a reduction in total sleep quantity, can result in daytime fatigue and somnolence, and a reduction in cognitive ability and overall functioning [6, 9]. Quality of sleep can be measured with disease-specific questionnaires of which the Leeds Sleep Evaluation Questionnaire (LSEQ) has frequently been used [20]. Other disease-specific HRQoL questionnaires for nocturia are the International Consultation on Incontinence QuestionnaireNocturia (ICIQ-N [21]) and the Nocturia-Quality of Life questionnaire (N-QoL, [22]). Generic QoL-questionnaires 


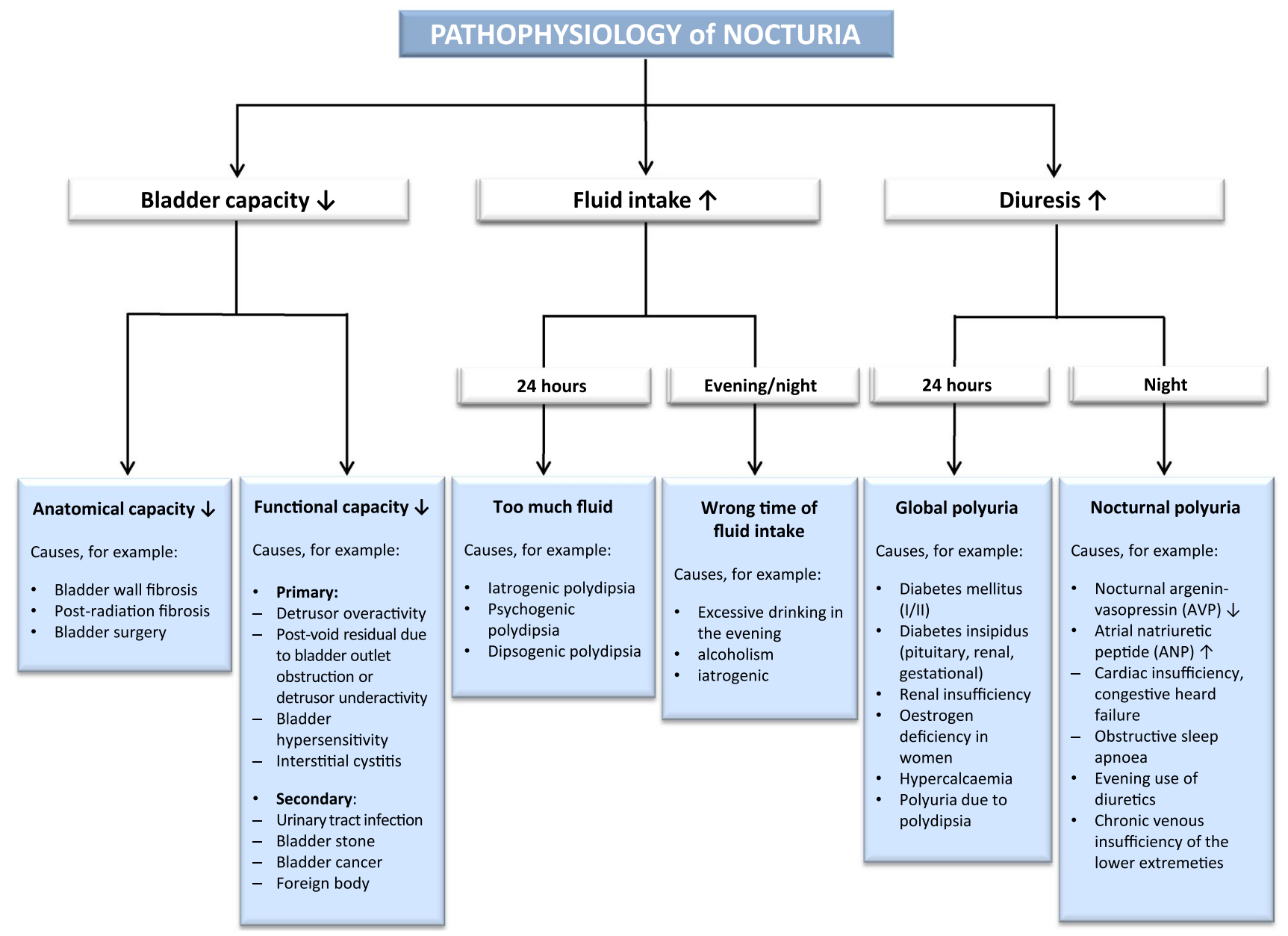

Fig. 1 Pathophysiology of nocturia (in line with the ICS standardization report [2]). Note that one or more causes may be present in the individual patient

can measure the deterioration of HRQoL due to nocturia in general, and results can be compared with patient groups without nocturia or other diseases (e.g., prostate cancer or diabetes mellitus). Generic QoL-questionnaires include the SF-36 or SF-12 questionnaires and the EQ-5D questionnaire.

\section{Treatment}

At the beginning, it is necessary to define the treatment goals. In patients with nocturia, the decrease of the number of nocturnal voiding episodes is relevant, but the decrease to $<2$ nocturia episodes/night, the prolongation of undisturbed sleep to $>4 \mathrm{~h}$ and the improvement of disease-specific QoL (such as sleep quality and the feeling after awakening) seem to be more important. There is not one single treatment which can cure all forms of nocturia. Treatment rather has to focus on the underlying pathophysiology (Fig. 1). For example, it appears unlikely that a patient with obstructive sleep apneoa will profit from bladder- or prostate-specific drugs, such as $\alpha$-blockers or antimuscarinics. Consequently, specific treatments have to be applied after careful assessment of the patient with nocturia (Figs. 2, 3). Nevertheless, behavioral treatments and lifestyle modifications appear beneficial in all patients despite differences in the underlying pathophysiology. Behavioral treatments and lifestyle interventions have not been subject of thorough clinical investigations and are rarely applied in routine practice, but they are cheap and easy and, therefore, should be included in every treatment strategy. Behavioral treatments include restriction of fluids a couple of hours before going to sleep, avoidance of caffeinated or alcoholic beverages in the evening, emptying the bladder before going to bed, leg elevation in case of edema of the lower extremities, moderate physical exercise and keeping warm in bed. It was shown in a prospective study on lifestyle interventions that more than $50 \%$ of patients reported improvement of nocturia when fluid restriction in the evening, limited time in 


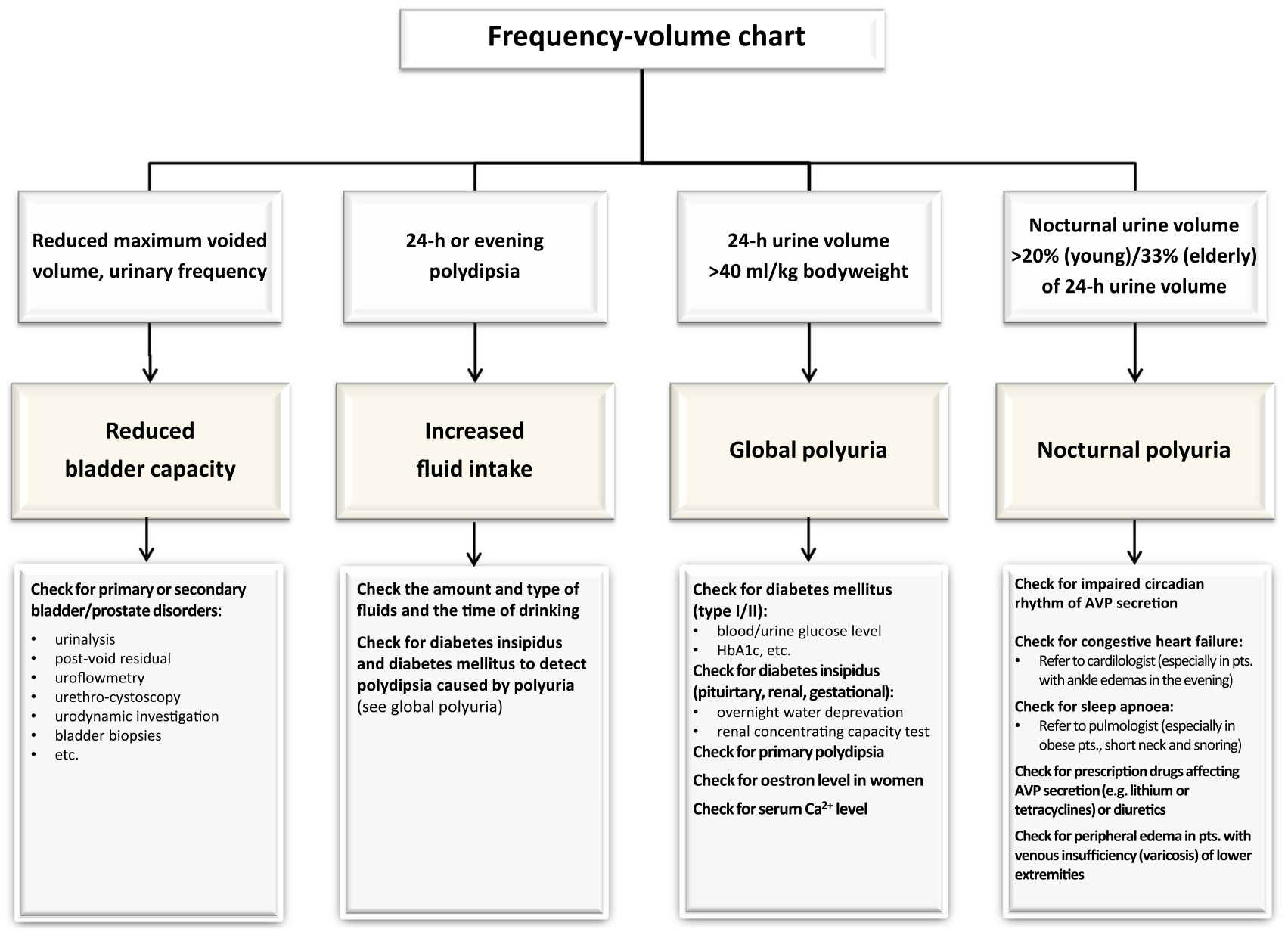

Fig. 2 Relevant information of frequency-volume charts (first line) which allows gross classification of the causes of nocturia (second line). Special investigations have to clarify the exact underlying pathophysiology of nocturia (third line)

bed, moderate exercise and keeping warm in bed were employed [23].

This topic issue of the World Journal of Urology on nocturia aims to analyze the effects of LUTS/BPH drugs on nocturia and, therefore, follows the common belief of urologists that nocturia is primarily caused by bladder or prostate disorders. The dedicated teams of authors analyzed all major drug classes used in urology to treat LUTS/BPH, i.e., $\alpha$-blockers (silodosin [24]), 5 $\alpha$-reductase inhibitors (dutasteride [25]), $\alpha$-blocker $+5 \alpha$-reductase inhibitor combination therapy (tamsulosin + dutasteride [26]), phosphodiesterase type 5 inhibitors (tadalafil [27]) and plant extracts (sabal serrulata + urtica dioica, PRO 160/120 [28]). Additionally, the effects of the arginine-vasopressin analogue desmopressin were analyzed in a cohort of LUTS/BPH patients with clinically relevant nocturia due to nocturnal polyuria [29]. For the purpose of this topic journal, databases of controlled, randomized phase II/III drug trials were used and evaluated homogeneously post hoc by using the same efficacy parameters to judge the effects on nocturia (e.g., number of nocturnal voids before vs. after treatment, number of patients with $<2$ nocturnal voids at treatment end and percent improved stable-worsened nocturia frequency). The results of the various LUTS/BPH drug classes on nocturia of this topic issue of the World Journal of Urology are summarized in Table 1. It became evident that (1) $>95 \%$ of patients with LUTS/BPH report about nocturia (nighttime voiding) with a frequency of $\geq 1$ and $>73 \%$ with a frequency $\geq 2$ times per night. Therefore, nocturia is an essential part of LUTS/BPH and appears more frequently than in community-dwelling men [4]. (2) The mean number of nocturnal voids per night in patients with the clinical diagnosis LUTS/BPH is between 2.3 and 3.0. This nocturia frequency indicates that the majority of patients with LUTS/BPH experience bother and reduced HRQoL from nocturia [3, 5]. (3) The reduction of the nighttime voiding frequency with LUTS/BPH drugs is only modest compared to placebo or active comparator, and the difference is approximately 0.2 voids per night, regardless of the drug class. (4) There is a high placebo effect when 


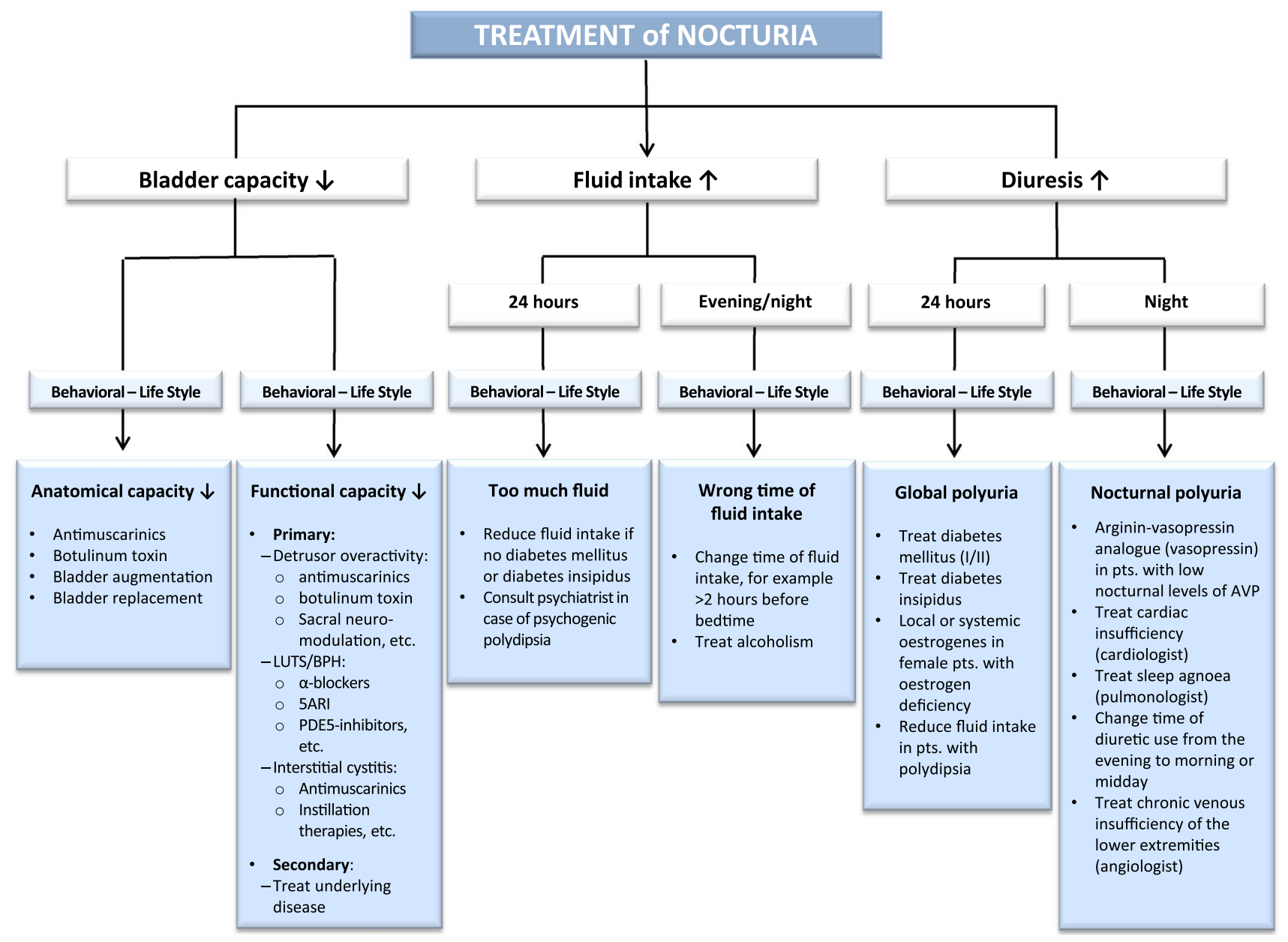

Fig. 3 Treatment path of nocturia based on the underlying pathophysiology (in line with the ICS standardization report [2]). Note that a patient may need more than one treatment of nocturia

treating nocturia in patients with LUTS/BPH, indicating that behavioral and lifestyle modifications under controlled study situations substantially add to treatment effects. (5) Despite the low mean reduction of nocturnal voids, 38$69 \%$ of patients report about nocturia improvement of $\geq 1$ void/night, and $26-44 \%$ of men with $\geq 2$ voids/night at baseline have $<2$ voids/night at study end, indicating a clinically relevant improvement of and only a minor amount of bother from nocturia $[3,5]$.

\section{Critical analysis of current assessment and treatment strategies}

This topic issue of the World Journal of Urology also elucidates relevant gaps in the assessment and treatment of patients with LUTS/BPH and nocturia. All trials were specifically designed to evaluate LUTS/BPH, and therefore, all trials only used assessment tools to evaluate the key parameters of LUTS/BPH (e.g., IPSS questionnaire, prostate volume, uroflowmetry) but, however, lack of specific instruments for the evaluation of nocturia (e.g., frequency-volume charts, measurement of hours of undisturbed sleep, quality of sleep or HRQoL questionnaires). Therefore, it is possible that the magnitude of the problem has not been correctly addressed in drug trials on LUTS/BPH; nocturia has been shown to be a relevant and bothersome part of LUTS/BPH and is mainly responsible for decreased HRQoL and health-care seeking behavior in these men [5]. During the recruitment of patients in drugs trials on LUTS/BPH, no specific attempt was made to look for other causes of LUTS, and therefore, other origins of nocturia beyond the bladder or prostate remained undetected in patients during LUTS/BPH checkup und study inclusion. It was shown in previous studies that nocturnal polyuria frequently appears together with LUTS/BPH [19]; consequently, it appears likely that only bladder or prostate disorders were correctly treated 
Table 1 Nocturia results with drugs used to treat lower urinary tract symptoms suggestive of benign prostatic hyperplasia (LUTS/BPH)

\begin{tabular}{|c|c|c|c|c|c|c|c|c|c|c|c|}
\hline \multirow[t]{2}{*}{ Parameter } & \multicolumn{2}{|c|}{$\alpha$-Blocker [24] } & \multicolumn{2}{|l|}{ 5ARI [25] } & \multicolumn{3}{|c|}{$\alpha$-blocker +5 ARI [26] } & \multicolumn{2}{|c|}{ PDE5 inhibitor [27] } & \multicolumn{2}{|c|}{ Plant extract [28] } \\
\hline & Silodosin & Placebo $^{\dagger}$ & Dutasteride & Placebo $^{\dagger}$ & $\begin{array}{l}\text { Combina- } \\
\text { tion }\end{array}$ & $\begin{array}{l}\text { Tamsulo- } \\
\sin ^{\dagger}\end{array}$ & $\begin{array}{l}\text { Dutas- } \\
\text { teride }^{\dagger}\end{array}$ & Tadalafil & Placebo $^{\dagger}$ & $\begin{array}{l}\text { PRO } \\
160 / 120\end{array}$ & Placebo $^{\dagger}$ \\
\hline $\begin{array}{l}\text { Study par- } \\
\text { ticipants } \\
(n)\end{array}$ & 837 & 642 & 2,121 & 2,123 & 1,569 & 1,575 & 1,578 & 752 & 748 & 147 & 145 \\
\hline $\begin{array}{l}\text { Study } \\
\text { duration } \\
\text { (weeks) }\end{array}$ & 12 & 12 & 24 & 24 & 48 & 48 & 48 & 12 & 12 & 24 & 24 \\
\hline $\begin{array}{l}\text { Mean IPSS } \\
\text { at base- } \\
\text { line }\end{array}$ & 21 & 21 & 17 & 17 & 16 & 16 & 16 & 18 & 17 & 18 & 18 \\
\hline $\begin{array}{l}\text { Nocturia } \\
\text { preva- } \\
\text { lence at } \\
\text { baseline } \\
(\%)\end{array}$ & 99.2 & 99.4 & 97.3 & 97.6 & 96.8 & 96.9 & 96.7 & 96.6 & 97.4 & 99.3 & 98.6 \\
\hline $\begin{array}{l}\geq 2 \text { noc- } \\
\text { turnal } \\
\text { voids at } \\
\text { baseline } \\
(\%)\end{array}$ & 85.3 & 86.0 & 76.2 & 75.5 & 75.3 & 75.3 & 75.9 & 73.3 & 74.2 & 85.7 & 81.4 \\
\hline $\begin{array}{l}\text { Mean } \\
\text { nocturia } \\
\text { frequency } \\
\text { at base- } \\
\text { line }(n)\end{array}$ & 3.0 & 3.0 & 2.4 & 2.4 & 2.4 & 2.4 & 2.4 & 2.3 & 2.3 & 2.4 & 2.4 \\
\hline $\begin{array}{l}\text { Mean } \\
\text { nocturia } \\
\text { frequency } \\
\text { at study } \\
\text { end }(n)\end{array}$ & $2.2^{*}$ & 2.4 & $2.1^{*}$ & 2.3 & 1.8 & 2.1 & 2.0 & $1.7 *$ & 1.9 & $1.6^{*}$ & 1.8 \\
\hline $\begin{array}{l}\text { Reduction } \\
\text { nocturia } \\
\text { frequency } \\
(n)\end{array}$ & $-0.8^{*}$ & -0.6 & $-0.28^{*}$ & -0.11 & $-0.5^{*}$ & -0.3 & -0.4 & $-0.5^{*}$ & -0.4 & $-0.8^{*}$ & -0.6 \\
\hline $\begin{array}{l}\Delta \text { nocturia } \\
\text { frequency } \\
\text { vs. com- } \\
\text { parator }\end{array}$ & $0.2^{*}$ & & $0.17 *$ & & $0.1 * / 0.2 *$ & & & $0.2^{*}$ & & $0.2^{*}$ & \\
\hline $\begin{array}{l}\text { Improve- } \\
\text { ment } \\
\text { nocturia } \\
(\% \mathrm{pts})\end{array}$ & $53^{*}$ & 43 & $38^{*}$ & 32 & $48^{*}$ & 39 & 43 & $48 *$ & 41 & $69^{*}$ & 52 \\
\hline $\begin{array}{l}\text { Stable } \\
\text { frequency } \\
\text { nocturia } \\
(\% \text { pts })\end{array}$ & 38 & 43 & 41 & 43 & 38 & 38 & 39 & 41 & 45 & 26 & 41 \\
\hline $\begin{array}{c}\text { Worsening } \\
\text { nocturia } \\
\text { (\% pts) }\end{array}$ & $9 *$ & 14 & $21^{*}$ & 26 & $15^{*}$ & 24 & 18 & 12 & 14 & 5 & 8 \\
\hline
\end{tabular}


Table 1 continued

\begin{tabular}{|c|c|c|c|c|c|c|c|c|c|c|c|}
\hline \multirow[t]{2}{*}{ Parameter } & \multicolumn{2}{|c|}{$\alpha$-Blocker [24] } & \multicolumn{2}{|l|}{ 5ARI [25] } & \multicolumn{3}{|c|}{$\alpha$-blocker + 5ARI [26] } & \multicolumn{2}{|c|}{ PDE5 inhibitor [27] } & \multicolumn{2}{|c|}{ Plant extract [28] } \\
\hline & Silodosin & Placebo $^{\dagger}$ & Dutasteride & Placebo $^{\dagger}$ & $\begin{array}{l}\text { Combina- } \\
\text { tion }\end{array}$ & $\begin{array}{l}\text { Tamsulo- } \\
\sin ^{\dagger}\end{array}$ & $\begin{array}{l}\text { Dutas- } \\
\text { teride }^{\dagger}\end{array}$ & Tadalafil & Placebo $^{\dagger}$ & $\begin{array}{l}\text { PRO } \\
160 / 120\end{array}$ & Placebo ${ }^{\dagger}$ \\
\hline $\begin{array}{l}<2 \text { Noctur- } \\
\text { nal voids } \\
\text { at study } \\
\text { end in pts. } \\
\text { with } \geq 2 \\
\text { voids at } \\
\text { baseline } \\
\text { (\% pts) }\end{array}$ & $29 *$ & 19 & $26^{*}$ & 19 & $34 *$ & 26 & 30 & $36^{*}$ & 26 & $44 *$ & 40 \\
\hline
\end{tabular}

The individual studies are presented in this topic issue on nocturia

$\dagger$ Comparator; * Drug versus comparator $p \leq 0.05$

with LUTS/BPH drugs, but nocturnal polyuria (and other causes) remained untreated. The observational study on desmopressin in patients with LUTS/BPH and nocturia due to nocturnal polyuria, which has also been included in this topic issue on nocturia, is in line with these statements [29]. It is therefore not surprising that nocturia is the most frequently reported (bothersome) symptom after prostate treatment, remaining in $68 \%$ in a series of dissatisfied, symptomatic patients after transurethral resection of the prostate [30].

The treatment results of LUTS/BPH drugs presented in this topic issue on nocturia do not answer the question whether trial participants were satisfied with the nocturia outcome. Although the average reduction of nocturia episodes per night was low and the effects versus placebo only modest, $50-70 \%$ of patients reported about a nocturnal voiding frequency $<2$ episodes per night with drug treatment (26-44\% of all patients with a baseline nighttime frequency $\geq 2$ ), suggesting only a minor or no problem with nocturia (anymore). It may also be that drugs used for LUTS/BPH prolong the hours of undisturbed sleep beyond the magical border of $4 \mathrm{~h}$ and, therefore, can substantially increase sleep quality without substantially decreasing the amount of nocturnal voids. Again, these clinical questions can only be answered by using nocturia-specific instruments. Future studies of patients with LUTS/BPH and nocturia should therefore also include nocturia-specific instruments to correctly classify the underlying pathologies for nighttime voiding and, hence, provide a rationale for the treatment of all LUTS causes. The author of this editorial comment recommend using, besides others, frequency-volume charts, measurement of the hours of undisturbed sleep, sleep evaluation questionnaires such as the LSEQ, and HRQoL questionnaires such as ICIQ-N or N-QoL in all future trials of LUTS/BPH patients with nocturia.

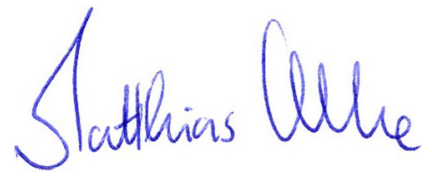

Matthias Oelke,

on behalf of the authors

\section{References}

1. Abrams P, Cardozo L, Fall M, Griffiths D, Rosier P, Ulmsten U, van Kerrebroeck P, Victor A, Wein A (2002) The standardisation of terminology of lower urinary tract function: report from the Standardisation Sub-Committee of the International Continence Society. Neurourol Urodyn 21:167-178

2. van Kerrebroeck P, Abrams P, Chaikin D, Donovan J, Fonda D, Jackson S, Jennum P, Johnson T, Lose G, Mattiasson A, Robertson G, Weiss J (2002) The standardisation of terminology in nocturia: report from the Standardisation Sub-Committee of the International Continence Society. Neurourol Urodyn 21:179-183

3. Tikkininen KA, Johnson TM 2nd, Tammela TL, Sintonen H, Huakka J, Huhtala H, Auvinen A (2010) Nocturia frequency, bother, and quality of life: how often is too often? A populationbased study in Finland. Eur Urol 57:488-496

4. Bosch JL, Weiss JP (2012) The prevalence and causes of nocturia. J Urol 189:S86-S92

5. Oelke M, Wiese B, Berges R (2014) Nocturia and its impact on health related quality of life and health care seeking behaviour in German community-dwelling men aged 50 years or older. World J Urol. doi:10.1007/s00345-014-1374-6

6. Stanley N (2005) The physiology of sleep and the impact of ageing. Eur Urol Suppl 3:17-23

7. Abrams P (2005) Nocturia: the effect on sleep and related health consequences. Eur Urol Suppl 3:1-7

8. Asplund R (2005) Nocturia: consequences for sleep and daytime activities and associated risks. Eur Urol Suppl 3:24-32 
9. Dijk DJ, Groeger JA, Stanley N, Deacon S (2010) Age-related reduction in daytime sleep propensity and nocturnal slow wave sleep. Sleep 33:211-223

10. Akerstedt T, Nilsson PM (2003) Sleep as restitution: an introduction. J Intern Med 254:6-12

11. Asplund R (1999) Mortality in the elderly in relation to nocturnal micturition. BJU Int 84:297-301

12. Bonnet MH, Arand DL (2003) Clinical effects of sleep fragmentation versus sleep deprivation. Sleep Med Rev 7:297-310

13. Stewart RB, Moore MT, May FE, Marks RG, Hale WE (1992) Nocturia: a risk factor for falls in the elderly. J Am Geriatr Soc 40:1217-1220

14. Vaughan CP, Brown CJ, Goode PS, Burgio KL, Allman RM, Johnson TM II (2010) The association of nocturia with incident falls in an elderly community-dwelling cohort. Int J Clin Pract 64:577-583

15. Nakagawa H, Niu K, Hozawa A, Ikeda Y, Kaiho Y, Ohmori-Matsuda K, Nakaya N, Kuriyama S, Ebihara S, Nagatomi R, Tsuji I, Arai Y (2010) Impact of nocturia on bone fracture and mortality in older individuals: a Japanese longitudinal cohort study. J Urol 184:1413-1418

16. Asplund R (2006) Hip fractures, nocturia, and nocturnal polyuria in the elderly. Arch Gerontol Geriatr 43:319-326

17. Temml C, Ponholzer A, Gutjahr G, Berger I, Marszalek M, Madersbacher S (2009) Nocturia is an age-independent risk factor for hip-fractures in men. Neurourol Urodyn 28:949-952

18. Holm-Larsen T (2014) The economic impact of nocturia. Neurourol Urodyn 33:S10-S14

19. Chang SC, Lin AT, Chen KK, Chang LS (2006) Multifactorial nature of male nocturia. Urology 67:541-544

20. Parrott AC, Hindmarch I (1980) The Leeds Sleep Evaluation Questionnaire in psychopharmacological investigations-a review. Psychopharmacology 71:173-179

21. McKown S, Abraham L, Coyne K, Gawlicki M, Piault E, Vats V (2010) Linguistic validation of the N-QOL (ICIQ), OAB-q (ICIQ), PPBC, OAB-S and ICIQ-MLUTS sex questionnaires in 16 languages. Int J Clin Pract 64:1643-1652

22. Abraham L, Hareendran A, Mills IW, Martin ML, Abrams P, Drake MJ, MacDanagh RP, Noble JG (2004) Development and validation of a quality-of-life measure for men with nocturia. Urology 623:481-486

23. Soda T, Masui K, Okuno H, Terai A, Ogawa O, Yoshimura $\mathrm{K}$ (2010) Efficacy of nondrug lifestyle measures for the treatment of nocturia. J Urol 184:1000-1004

24. Eisenhardt A, Schneider T, Cruz F, Oelke M (2014) Consistent and significant improvements of nighttime voiding frequency (nocturia) with silodosin in men with LUTS suggestive of BPH-pooled analysis of three randomized, placebo-controlled, double-blind phase III studies. World J Urol. doi:10.1007/ s00345-013-1228-7

25. Oelke M, Roehrborn CG, D'Ancona C, Wilson TH, Castro R, Manyak M (2014) Nocturia improvement with dutasteride in men with lower urinary tract symptoms suggestive of benign prostatic hyperplasia (LUTS/BPH): a pooled analysis of three phase III studies. World J Urol. doi:10.1007/s00345-014-1316-3

26. Oelke M, Roehrborn CG, D'Ancona C, Wilson TH, Castro R, Manyak M (2014) Nocturia improvement in the combination of Avodart ${ }^{\circledR}$ and tamsulosin (CombAT) study. World J Urol. doi:10.1007/s00345-014-1296-3

27. Oelke M, Weiss JP, Mamoulakis C, Cox D, Ruff D, Viktrup L (2014) Effects of tadalafil on night-time voiding (nocturia) in men with lower urinary tract symptoms suggestive of benign prostatic hyperplasia: analyses of pooled data from four randomized, placebo-controlled clinical studies. World J Urol. doi:10.1007/ s00345-014-1255-z

28. Oelke M, Berges R, Schläfke S, Burkart M (2014) Fixed dose combination of sabal and urtica improves nocturia in men with LUTS suggestive of BPH-re-evaluation of four controlled clinical studies. World J Urol. doi:10.1007/s00345-014-1338-x

29. Berges R, Höfner K, Gedamke M, Oelke M (2014) Impact of desmopressin on nocturia due to nocturnal polyuria in men with lower urinary tract symptoms suggestive of benign prostatic hyperplasia (LUTS/BPH). World J Urol. doi:10.1007/ s00345-014-1381-7

30. Seaman EK, Jacobs BZ, Blaivas JG, Kaplan SA (1994) Persistence or recurrence of symptoms after transurethral resection of the prostate: a urodynamic study. J Urol 152:935-937 